\title{
Experimental and analytical study of an innovative integrated dual-source evaporator for solar-assisted heat pumps
}

\author{
Riccardo Simonetti*, Luca Molinaroli, Giampaolo Manzolini \\ Dipartimento di Energia, Politecnico di Milano, Via Lambruschini 4, 20156 Milano, Italy
}

\section{A R T I C L E I N F O}

\section{Keywords:}

Performance analysis

Experimental analysis

Optimal design

$\mathrm{PV} / \mathrm{T}$ collector

DSHP system

\begin{abstract}
A B S T R A C T
Energy efficiency is an effective way to produce energy reducing the impact of fossil fuels in the energy sector. A promising solution for residential application consists of producing domestic hot water and space heating using Solar-Assisted Heat Pump. This work analyzes the performance of a Solar-Assisted Heat Pump with an innovative Integrated Dual-Source Evaporator connected to Photovoltaic/Thermal modules. The concept is firstly validated in laboratory where the Solar-Assisted Heat Pump is operated in real environmental conditions. Then, a numerical model is developed in Matlab ${ }^{\circledast}$ to identify the optimal design of the Integrated Dual-Source Evaporator. Numerical results show that the performance of the system are significantly affected by the solar irradiance and in a wide operating range the photovoltaic production overcomes the Heat Pump consumptions. Compared to a standard Air-Source Heat Pump, the proposed concept shows up to 14\% higher Coefficient of Performance.
\end{abstract}

\section{Introduction}

In the last years, it has been registered an increased energy share of renewable energy for heat and electricity production together with an increase of fossil fuels consumptions (IEA, 2018a,b). In this scenario, HP can reduce the primary energy consumptions from fossil fuels for heating and cooling sectors (REN21, 2018). The most diffused Heat Pump (HP) technologies, air-source and ground-source, cannot be considered the ultimate solution in terms of efficiency and costs. The Air-Source Heat Pump (ASHP) is cheap and flexible in the installation site, but performance is strongly influenced by the environmental conditions (the lower the ambient temperature, the higher the required thermal load but the lower is the performance) whereas the GroundSource Heat Pump (GSHP), even if performance is very high and stable along the year, system costs are very relevant and the installation is case-specific and not always possible (IEA, 2011).

The integration of solar energy with HP, concept also known as Solar-Assisted Heat Pump (SAHP) could: (i) improve the efficiency of this technology, (ii) maintain low costs and high installation flexibility and (iii) exploit solar radiation more efficiently, increasing its penetration in the residential sector (Buker and Riffat, 2016; Lazzarin, 2012). The SAHP concept consists of solar collectors which can either solar thermal collectors or hybrid Photovoltaic/Thermal (PV/T) providing the heat to the evaporator. Between solar thermal modules and $\mathrm{PV} / \mathrm{T}$, the former guarantees higher thermal collection while the latter combines electricity and heat production, with benefits for the solar cells efficiency (Bombarda et al., 2016).

Different level of integration between the heat pump and the solar collector have been proposed in literature. The simplest configuration, called Indirect Solar-Assisted Heat Pump (I-SAHP), consists of the solar modules connected to the evaporator (Simonetti et al., 2017). This configuration has low capital costs but limited operating range as the only heat source for the evaporator is the solar energy. Nuntaphan et al. (2009) have experimentally analyzed the performance of a I-SAHP coupled with solar flat collectors including a hot water storage of $300 \mathrm{dm}^{3}$. Results demonstrated higher system efficiency compared to a traditional configuration (only thermal panels), with advantages up to $40 \%$. Li et al. (2014) have analyzed a I-SAHP with flat solar collectors for residential heating. The study was done with a model developed in TRNSYS and results demonstrated that $68.1 \%$ of the heating and domestic hot water demand can be covered by the SAHP. Moreover, the performance is increased by $140 \%$ compared to a standard HP and the energy saving is close to $52 \%$. Liu et al. (2014) have investigated a system with a I-SAHP and vacuum solar collectors for residential use. An experimental set-up was used to validate a model built in TRNSYS. The study showed that, considering a system designed for a solar fraction of $20 \%$, about $66 \%$ of the thermal load can be covered in the worst month and it is possible to reduce the energy consumption by $55 \%$ compared to a traditional system with a boiler. Calise et al. (2016) studied the performance of a three-generation system composed by a I-

\footnotetext{
* Corresponding author.

E-mail address: riccardo.simonetti@polimi.it (R. Simonetti).
} 


$\begin{array}{ll}\text { Nomenclature } \\ \dot{m} & \text { mass flow rate }[\mathrm{kg} / \mathrm{s}] \\ \dot{Q} & \text { thermal power }[\mathrm{W}] \\ \dot{V} & \text { volumetric flow rate }\left[\mathrm{m}^{3} / \mathrm{s}\right] \\ \dot{W} & \text { electrical power }[\mathrm{W}] \\ A & \text { area }\left[\mathrm{m}^{2}\right] \\ a_{1} & \text { thermal losses coefficient }\left[\mathrm{W} /\left(\mathrm{m}^{2} \mathrm{~K}\right)\right] \\ c_{p} & \text { specific heat capacity }[\mathrm{J} /(\mathrm{kgK})] \\ G_{r} & \text { specific flow rate of a single channel }\left[\mathrm{kg} /\left(\mathrm{m}^{2} \mathrm{~s}\right)\right] \\ G_{T} & \text { solar irradiance on titled surface }\left[\mathrm{W} / \mathrm{m}^{2}\right] \\ h & \text { specific enthalpy }[\mathrm{J} /(\mathrm{kg})] \\ h_{\text {conv }} & \text { heat transfer coefficient }\left[\mathrm{W} /\left(\mathrm{m}^{2} \mathrm{~K}\right)\right] \\ k & \text { thermal conductivity }[\mathrm{W} /(\mathrm{mK})] \\ p & \text { pressure }[\text { Pa] } \\ R & \text { thermal resistance }[\mathrm{K} / \mathrm{W}] \\ T & \text { temperature }\left[{ }^{\circ} \mathrm{C}\right] \\ t & \text { thickness }[\mathrm{m}] \\ U & \text { overall heat transfer coefficient }\left[\mathrm{W} /\left(\mathrm{m}^{2} \mathrm{~K}\right)\right] \\ X & \text { glycol fraction }[\text { dimensionless }]\end{array}$

Greek symbols

$\begin{array}{ll}\chi & \text { vapor quality [dimensionless] } \\ \Delta p & \text { pressure drops [Pa] } \\ \Delta T & \text { temperature difference [K] } \\ \epsilon & \text { effectiveness [dimensionless] } \\ \eta & \text { efficiency [dimensionless] } \\ \gamma & \text { electrical power coefficient [\%/K] } \\ \rho & \text { density [kg } / \mathrm{m}^{3} \text { ] } \\ \sigma & \text { standard deviation } \\ \xi & \text { void fraction [dimensionless] }\end{array}$

SAHP integrating PV/T solar modules for heating/cooling loads in a residential application. The model, developed in TRNSYS, showed that the system can cover the entire thermal load and the average performance is $30 \%$ higher than a standard HP. All these results confirmed the good performance of the I-SAHP system, but pointed out its strong dependence from the environmental conditions, especially from solar radiation. Finally, a previous study of a I-SAHP was performed with a numerical model, confirming the potentialities of this technology but also pointing out the performance problems during cloudy days as well as during the night (Simonetti et al., 2017).

Similar to the indirect configuration is the direct expansion configuration where the working fluid of the HP evaporates directly in the solar collectors (Shi et al., 2019). This configuration reduces the equipment costs as the evaporator coincides with the solar modules, maximizing their efficiency, but has the limits of the indirect one (very low performance in cloudy days and during night time) plus the temperature increase of the fluid during summer period with pressure issues, due to the high irradiation heating up the panels and the few working hours of the HP related to the low thermal heat required.

In order to overcome the issues of the direct and indirect configurations, the Dual-Source Heat Pump (DSHP) technology was introduced. In the dual-source configuration, the heat to the evaporator can be provided by both air and solar energy because the HP is equipped with two evaporators, one connected to the air-source and one to the solar-source. The two evaporators can be arranged both in parallel and in series, with different operational issues: the parallel configuration requires to balance the refrigerant charge between the two evaporator when one is switched off and the other is turn on during operation. The serial arrangement bounds the evaporation temperature to the air temperature, reducing the benefits coming from the solar-source part.

An experimental study of a solar PV/T integrated in an indirect DSHP in Shanghai demonstrated that the system can operate efficiently

\section{Subscripts}

$\begin{array}{ll}\text { a } & \text { air } \\ \text { acc } & \text { acceleration } \\ \text { amb } & \text { ambient } \\ \text { c } & \text { condensation } \\ \text { cell } & \text { cell } \\ \text { comp } & \text { compressor } \\ \text { cond } & \text { condenser } \\ e & \text { evaporation } \\ \text { el } & \text { electrical } \\ f & \text { fluid } \\ \text { fan } & \text { fan } \\ \text { fric } & \text { friction } \\ \text { in } & \text { inlet } \\ \text { liq } & \text { liquid } \\ \text { opt } & \text { optical } \\ \text { out } & \text { outlet } \\ \text { panels } & \text { panels } \\ \text { plate } & \text { plate } \\ \text { PR } & \text { primary } \\ \text { pump } & \text { pump } \\ \text { REF } & \text { reference } \\ \text { refr } & \text { refrigerant } \\ \text { SC } & \text { secondary } \\ \text { sh } & \text { superheating } \\ \text { sub } & \text { subcooling } \\ \text { vap } & \text { vapor } \\ \text { wall } & \text { wall } \\ \text { water } & \text { water } \\ & \end{array}$

in both air and air plus solar modes, reaching high performance and increasing the electrical conversion efficiency of PV/T panels by $10.3 \%$ (Qu et al., 2016). Another work (Croci et al., 2017) performed an annual simulation in TRNSYS of an indirect DSHP compared to conventional ASHP. The DSHP concept can provide significant energy savings for a single family building placed in Milan, with a decreased yearly electrical energy consumption by $12 \%$ and withdrawal from the grid of $34 \%$. Cai et al. (2017) have numerically analyzed an indirect DSHP in a parallel asset with PV/T panels. Results showed that the distribution of the refrigerant fluid in the two evaporator is a key problem, and it strongly depends on the environmental conditions. However, the simulated system can obtain efficient operation with the average Coefficient Of Performance (COP) above 2 under the ambient temperature of $10^{\circ} \mathrm{C}$ and solar irradiation of $100 \mathrm{~W} / \mathrm{m}^{2}$. A very recent work (Besagni et al., 2019) have experimental demonstrated the feasibility of an indirect DSHP in a residential context, settled in Milan. The machine asset was with the two sources disposed in series and the possibility to feed directly the Domestic Hot Water (DHW) storage with PV/T panels. The system was able to maintain high efficiencies in the different seasons, with average performance in terms of COP equal to 3 . Moreover, approximately $63 \%$ of the heat needed by the DHW storage tank was provided directly by the PV/T panels and the daily-averaged energy consumptions were deduced by $15.4 \%$ compared to a standard ASHP. The main drawbacks of these solutions are a major system complexity, especially in the parallel layout, and a higher cost.

A further option of DSHP consists of designing a single evaporator with both air and solar sources. This concept, called Integrated DualSource Heat Pump (I-DSHP), can combine the benefits of a DSHP with the simplicity of a I-SAHP. One of the first works on I-DSHP was performed by Wang et al. (2015) who experimentally evaluated the concept when connected to PV/T panels. Results showed that the COP of the I-DSHP, was higher than the one of a ASHP and that the PV/T 
modules took advantages in terms of efficiency too. An air-water IDSHP system was built by Xu et al. (2018) with two different evaporators design to identify the circuitries with higher performance. The analysis has found that performance can be increased by $6.3 \%$ to $9.8 \%$ by developing a more optimized circuitry of the combined heat exchanger. Finally, Long et al. (2019) studied both from experimental and numerical point of view a I-DSHP, pointing out an increase of performance by $15 \%$ compared to air-source mode. Two evaporators configurations were also analyzed, identifying in the refrigerant-water-refrigerant type evaporator a better anti-frosting capability when operating with low water temperatures.

To sum up, the amount of works available in the open literature related to the innovative I-DSHP is still very limited with most of them performing experimental analysis. The circuitry is predefined and a limited efforts were devoted to modeling aspects to investigate the optimal design, especially for the entire HP system under different environmental conditions. In this work, the innovative concept is studied both from experimental point of view to further demonstrate the feasibility of the concept and with an analytical model to optimize the circuitry configuration.

The paper is structured as follow. In Section 2, the concept and the advantages of the innovative HP system are presented and the layout of the entire system is described. In Section 3, the experimental campaign is presented, describing the set-up and the procedure together with the main results. Section 4 outlines the mathematical analysis, starting from the model description, listing the different circuitries studied and ending with the results interpretation. Finally, in Section 5 conclusions are presented.

\section{Concept}

The Integrated Dual-Source Evaporator (I-DSE) concept is based on the finned-tube heat exchanger technology, the same adopted in the evaporator of a conventional ASHP, with additional water rows. In this configuration, the air is the heat transfer medium from the water to the refrigerant: the air flows across the water tubes heats up, and then transfers the heat to the refrigerant. In general, the water can be heated by any solar collector, but in this work, the water circuit is connected to a PV/T field, where both heat and electricity are produced.

The aim of using I-DSE is to combine the advantages of the ASHP and the I-SAHP while limiting the HP complexity and preventing the issues related to the double-evaporator of the I-DSHP above-mentioned. As ASHP, the I-DSE system can work in every condition without requiring any additional component (i.e. boiler) and guaranteeing the fulfillment of the heating demand. The I-SAHP system can exploit the solar energy increasing the evaporation temperature and using the electricity produced by the $\mathrm{PV} / \mathrm{T}$ panels to reduce the energy demand of the compressor of the HP and increasing the self-consumption of the entire system. Combining these two technologies it is possible to maintain high performance during the day and extend the operation of a I-SAHP system also when the solar irradiance is low.

Depending on the thermal energy produced by $\mathrm{PV} / \mathrm{T}$ panels, the integrated dual-source system (I-DSE plus standard HP components) can work as follow:

- with low irradiance, the temperature of the water coming from the $\mathrm{PV} / \mathrm{T}$ field is not sufficient to produce an useful effect inside the IDSE. The system works as an standard ASHP, and the PV/T field produces only electricity;

- with high irradiance, an extra heat from PV/T panels enters in the HP cycle, increasing the performance of the HP system and also of the $\mathrm{PV} / \mathrm{T}$ panels because of the reduction of the mean temperature of the working fluid.

The low and high conditions depend on the ambient temperature as it will be clear in the operating maps reported in the results section. Fig. 1 shows an example of the circuitry of the I-DSE concept: between the two rows of the refrigerant fluid (in green), two other rows are

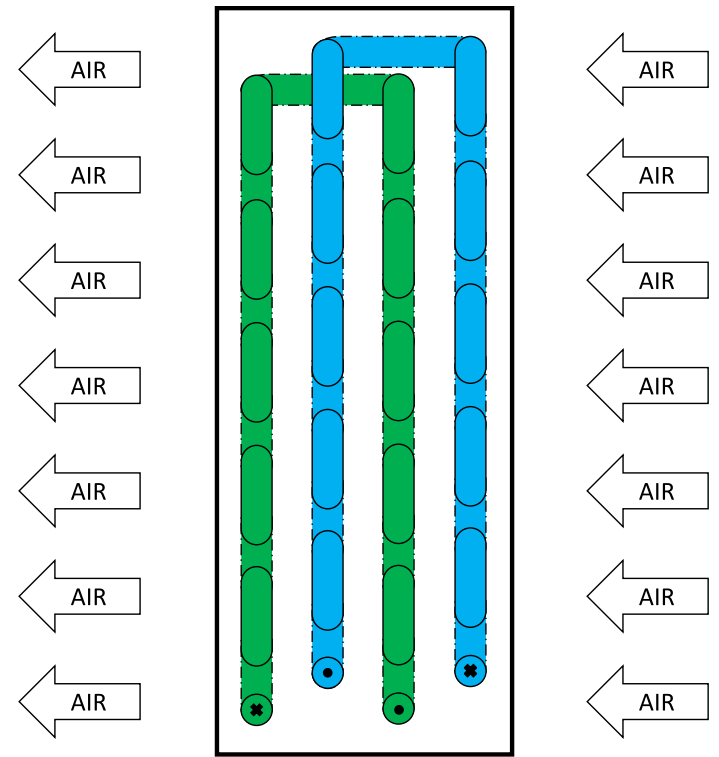

Fig. 1. Representation of the circuitry scheme of the innovative evaporator, refrigerant rows in green and water plus glycol mixture rows in blue. (For interpretation of the references to color in this figure legend, the reader is referred to the web version of this article.)

added where the water + glycol mixture flows (in blue) making a counterflow configuration to maximize the performance.

The main key performance indicator used for the analysis of this system is the COP which is defined as reported in the following equation:

$C O P=\frac{\dot{Q}_{\text {cond }}}{\dot{W}_{\text {comp }}+\dot{W}_{\text {fan }}+\dot{W}_{\text {pump }}}=\frac{\dot{V}_{\text {cond }} \cdot \rho \cdot c_{p} \cdot\left(T_{\text {cond }, \text { out }}-T_{\text {cond }, \text { in }}\right)}{\dot{W}_{\text {comp }}+\dot{W}_{\text {fan }}+\dot{W}_{\text {pump }}}$

Moreover, a modified version of the COP is adopted to account for the electrical production of the $\mathrm{PV} / \mathrm{T}$ modules that can reduce the electrical consumption of the HP and to point out the benefits of cooling the panels compared to a standard Photovoltaic (PV) technology. The equation of modified COP, COP*, is here reported:

$C O P^{*}=\frac{\dot{Q}_{\text {cond }}}{\dot{W}_{\text {comp }}+\dot{W}_{\text {fan }}+\dot{W}_{\text {pump }}-\dot{W}_{\text {panels }}} \quad$ where $\quad \dot{W}_{\text {panels }}=\sum_{i}^{N_{\text {panels }}} \dot{W}_{\text {panel }, i}$

\section{Experimental analysis}

\subsection{Experimental facility}

The experimental set-up used in the present work is an outdoor laboratory whose layout is shown in Fig. 2. The experimental facility consists of: (i) a cold water loop (blue line), (ii) a prototype HP with a integrated dual-source evaporator and (iii) a hot water loop (red line).

In the cold loop, the water at the outlet of the roll-bond PV/T collectors enters the innovative evaporator of the HP, where it is cooled and sent back to the PV/T modules. The heat provided by the PV/T field and the air acts as the low temperature heat source of the HP and the evaporation temperature achieved by refrigerant fluid may be higher than the ambient one.

In the hot loop, the water is heated inside the condenser of the HP and sent to a hot storage tank. A three-ways valve controls the amount of fluid directed to the inlet of the condenser or through an air dry cooler. The fans of the air dry cooler are automatically controlled to maintain the inlet temperature of the condenser of the HP stable and equal to the desired value, which was settled to $30^{\circ} \mathrm{C}$ in this work. This is necessary in order to have the performance of the system only as a function of the evaporation temperature and, consequently, of the environmental conditions. 


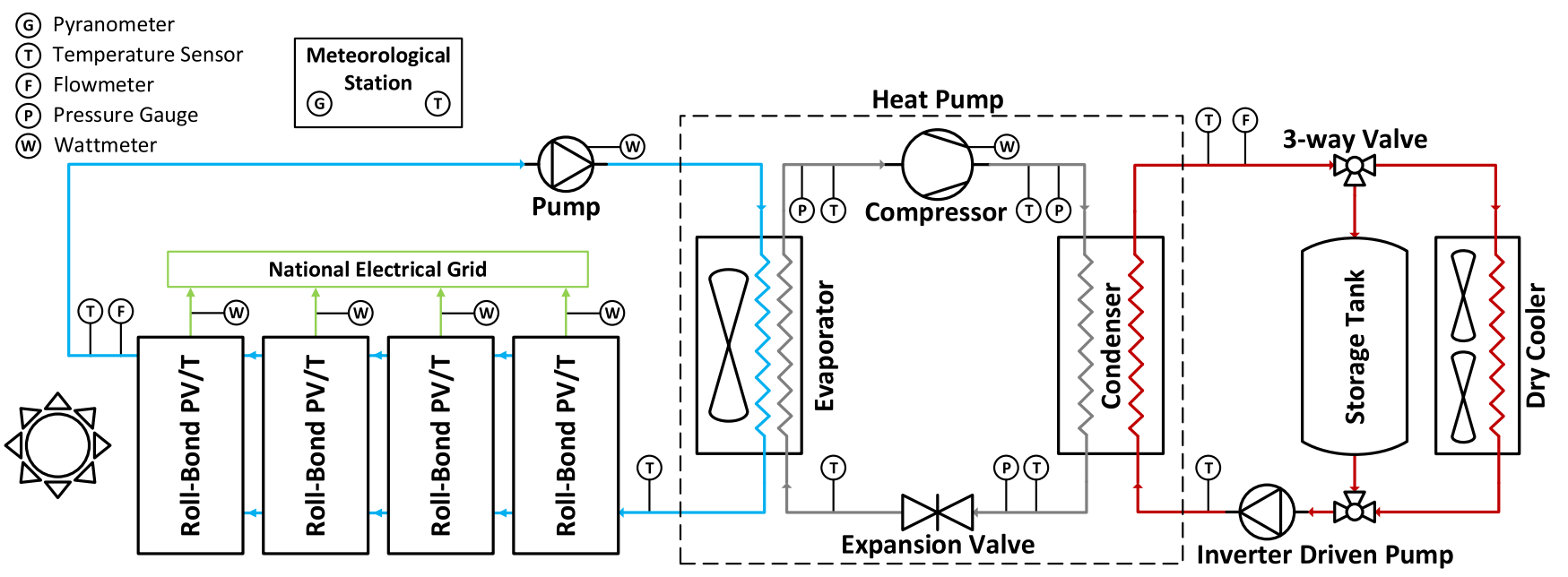

Fig. 2. Schematic of the integrated dual-source evaporator system.

The system is composed by commercial PV/T panels and a prototype HP made by assembling commercially available components. The solar field counts four standard PV modules $(250 \mathrm{~W}$ of peak power each) with polysilicon solar cells and a roll-bond heat exchanger attached to the back (SoLink, 2018). The heat exchanger is covered with an insulating layer and each module is connected with its own inverter, in order to separately measure the electric performance of each module. Details of the PV/T panels are shown in Fig. 3.

The HP is assembled with a rotary compressor (MasterFlux, 2017), a brazed plate condenser (Honda, 2018), an electronic expansion valve (Carel, 2018) and the innovative evaporator (LuVe, 2018). Fig. 4 shows the four components of the prototype HP while the model and the manufacturer of all the components are reported in Table 1.

It is worth pointing out that, being the HP a prototype, the performance of this system will not be comparable with standard machines. In fact, the integrated dual-source evaporator was purchased from a company but designed for other applications. The system was assembled with components selected on the limitations of the laboratory (dimension and weight). As consequence of that, the performance are penalized by the non-optimal sizing of the system. However, the objectives of the experimentation was to validate the concept, to carry out a comparison between a standard technology and the innovative concept studied, but certainly not to obtain a system with high performance. The real potentialities of the system are assessed through the numerical analysis shown in Section 4.

\subsection{Measurement apparatus}

The objective of the experimentation is to evaluate the performance of the integrated dual-source system at different ambient and operating conditions (air-source or dual-source) and demonstrate the feasibility of the innovative concept.

Therefore, the measured parameters for determining the COP are the condenser inlet and outlet temperatures, the water flow rate and the electrical consumptions (compressor, fan and circulating pump in the secondary loop) as well as the PV/T production.

$T_{\text {cond,out }} / T_{\text {cond,in }}$ Temperature measurements are performed with thermoresistances Pt100 inserted in the hydraulic circuit

$\dot{V}_{\text {cond }}$ Volumetric flow rate measurements are performed with a flowmeter based on the passage of liquid through two oval geared rotors: the rotation of a magnet creates a pulse output

$\dot{W}_{\text {comp }}$ The electrical consumption of the compressor is measured using a wattmeter which accounts also for the inverter conversion losses

$\dot{W}_{f a n}$ The fan electric consumption is evaluated using a correlation determined in situ with a characterization champaign using a vane anemometer

$\dot{W}_{\text {pump }}$ The electrical load of the circulating pump is determined starting from the mixture flow rate and using the pump characteristic curve from the website of the manufacturer (Grundfos, 2018) $\dot{W}_{\text {panels }}$ The electrical production of the solar field is measured using wattmeters present inside the inverters that $\mathrm{PV} / \mathrm{T}$ panels are equipped with.

Fig. 5 reports also the correlations to evaluate fan and circulating pump electrical consumptions. Fan consumption is calculated from the fan speed, ranging between $0 \%$ and $100 \%$, which is set from the control panel of the laboratory. The circulating pump consumption is
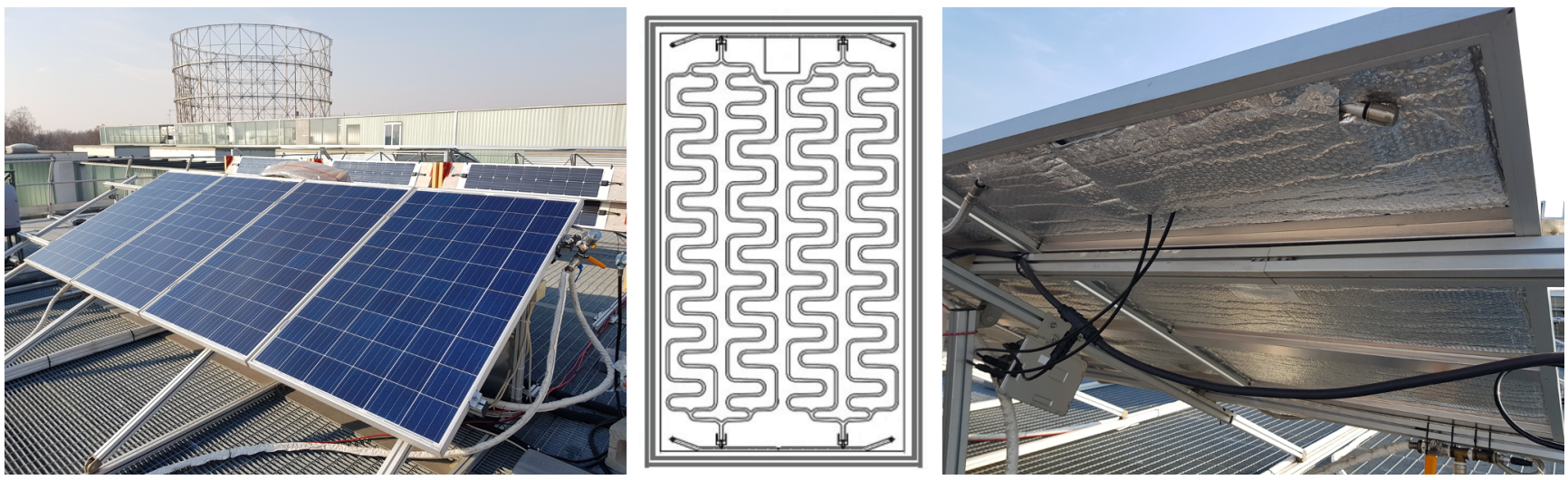

Fig. 3. Front, circuitry and back of PV/T modules. 


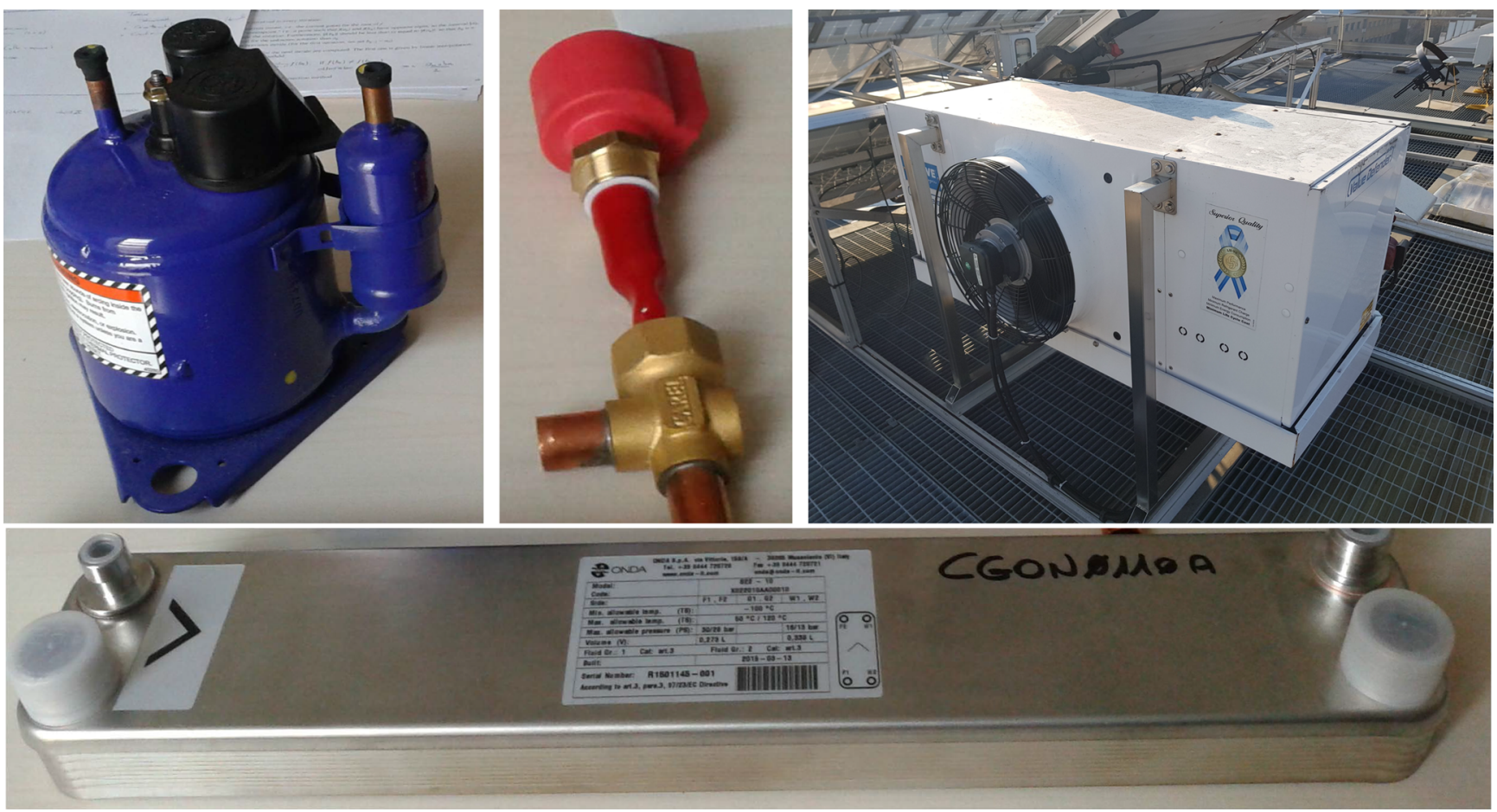

Fig. 4. Compressor, expansion valve, integrated dual-source evaporator and condenser of the prototype HP.

Table 1

Model and manufacturer of the main components of the experimental set-up.

\begin{tabular}{lr}
\hline Compressor & SIERRA02-0434Y3 - MasterFlux \\
Expansion Valve & E2V11SSF00 - Carel \\
Evaporator & CHS-CS45H 1400-10E - LuVe \\
Condenser & S22-10 - Onda \\
PV $/$ T Modules & HYBRID POWER - SoLink \\
- Dimensions $(\mathrm{L} \times \mathrm{W} \times \mathrm{D})$ & $0.991 \times 1.649 \times 0.035 \mathrm{~m}$ \\
\hline
\end{tabular}

determined from the website of the manufacturer (Grundfos, model UPS 25-80 180), where a tool is available to find working point of the pump with a specific flow rate, fluid temperature and volume glycol fraction. A map, obtained varying the first two parameters, was adopted in the analysis.

Another important parameter to be monitored is the temperature of the superheated vapor: the higher this value and the better is the performance of the HP cycle, because the higher is the evaporation temperature with a constant superheating, neglecting the influence of the auxiliaries (fan, circulating pump). The use of an electronic expansion valve permits to maintain a constant superheating degree of the refrigerant in all the conditions, allowing to analyze the superheated vapor temperature behavior instead of the evaporation one. A system of thermocouples was used to monitor the temperatures of the refrigerant and the air temperature at the inlet of the integrated dual-source evaporator, allowing to evaluate the effects of the extra heat coming from the solar field on the HP functioning.

Detailed data of the instruments are reported in Table 2.

Finally, the laboratory is equipped with a weather station to monitor and collect ambient data (Bombarda et al., 2016). The station is equipped with the following measurement instruments:

- two pyranometers, which determine the global solar irradiance on the horizontal plane (one first standard and one secondary standard)

- a first standard pyranometer with an occultation band, which detects the diffusive irradiance

- a secondary standard pyranometer that measures the global solar irradiance on a surface tilted $30^{\circ}$

- a thermohygrometer, measuring the air temperature and the atmospheric humidity

- a wind anemometer to detect wind speed and direction
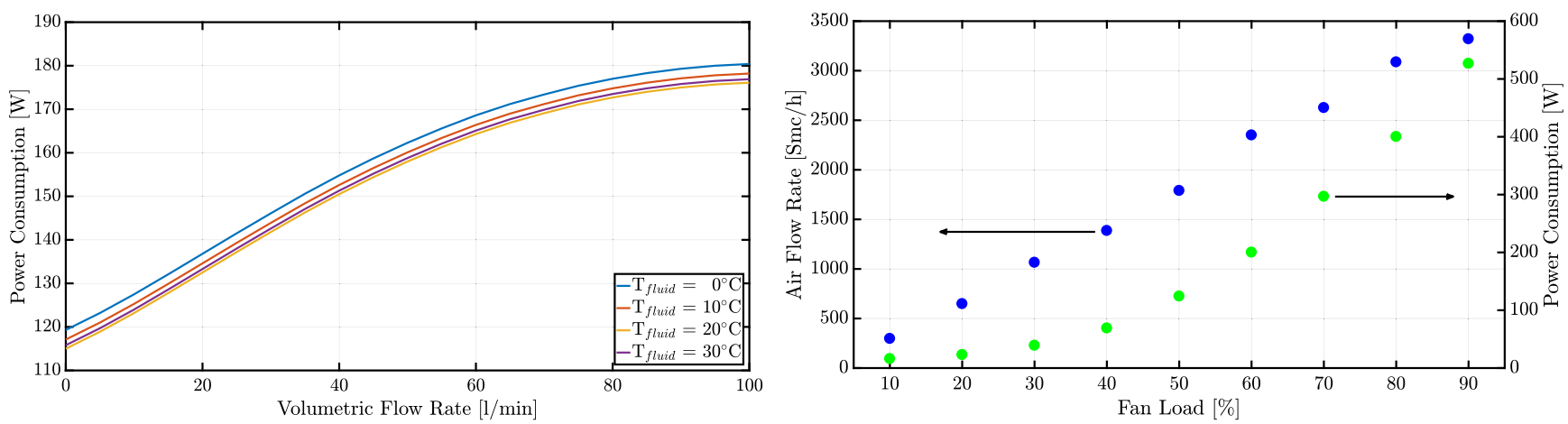

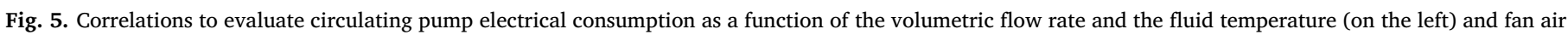

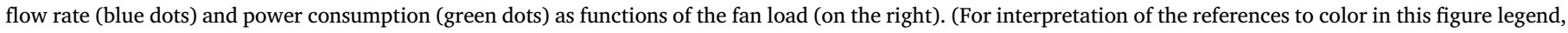
the reader is referred to the web version of this article.) 
Table 2

Technical informations of the measurement instruments.

\begin{tabular}{|c|c|c|c|}
\hline Instrument & Model & Range & Uncertainty \\
\hline Thermocouple & Type T & $-270^{\circ} \mathrm{C}$ to $400^{\circ} \mathrm{C}$ & $0.1^{\circ} \mathrm{C}$ \\
\hline Thermoresistance & Pt 100 & $-50^{\circ} \mathrm{C}$ to $250{ }^{\circ} \mathrm{C}$ & $1 / 10 \mathrm{~B}$ \\
\hline Flowmeter - Hot Loop & Flomec - OM008 & $0.25-91 / \mathrm{min}$ & $\pm 1 \% \mathrm{RV}$ \\
\hline Flowmeter - Cold Loop & Huba-Control - 210 & $0.9-151 / \mathrm{min}$ & $\pm 1 \%$ FS \\
\hline Wattmeter & CEWE - DPT221-401 & $<1100 \mathrm{~W}$ & $\pm 0.5 \% \mathrm{FS}$ \\
\hline Wattmeter (Inverter) & Power One - Aurora Micro & $<250 \mathrm{~W}$ & $\pm 1 \% \mathrm{RV}$ \\
\hline Pyranometer & LSI - DPA 252 & $<2000 \mathrm{~W} / \mathrm{m}^{2}$ & $<2 \% \mathrm{RV}$ \\
\hline Thermohygrometer & LSI - DMA 875 & $-30^{\circ} \mathrm{C}$ to $70^{\circ} \mathrm{C}$ & $1 / 3 \mathrm{~B}$ \\
\hline
\end{tabular}

A National Instrument ${ }^{\mathrm{TM}}$ cRIO rack is used for data acquisition. Data are sent via LAN to a host PC where a LabVIEW ${ }^{\mathrm{TM}}$ program is used to read, visualize, analyze and store the measurements. Data are read every second and saved in a file for further analysis and elaboration.

\subsection{Experimental conditions}

The experimental setup is located in the North of Italy, at SolarTech laboratory on the roof of the Department of Energy of Politecnico di Milano; whose geographical coordinates are latitude $\mathrm{N} 45^{\circ} 30^{\prime} 10.588^{\prime \prime}$ and longitude E $9^{\circ} 9^{\prime} 23.677^{\prime \prime}$. PV/T panels are tilted of an angle of $27^{\circ}$ and oriented from the South direction of an angle of $-3^{\circ}$ (positive clockwise). Tests were carried out in the period from 13th to 27th of February 2018, 7 days of experimentation, with ambient temperature between $-1.8^{\circ} \mathrm{C}$ and $10.2^{\circ} \mathrm{C}$ and solar irradiance on the horizontal plane between $21.7 \mathrm{~W} / \mathrm{m}^{2}$ and $756.1 \mathrm{~W} / \mathrm{m}^{2}$. The selected days are representative of a real operating conditions of the HP providing heat for a residential application in winter.

\subsection{Methodology}

The I-DSHP system is tested in real environmental conditions (e.g. with variable irradiance, wind speed and ambient temperature). This requires the development of a methodology to estimate its performance to avoid the inclusion of outliers and transient phenomena. The procedure starts with the selection of the days with suitable weather conditions meaning high and nearly constant solar radiation as well as negligible wind speed. All the measured data are stored every second, then are imported in MATLAB $^{\circledR}$ where the average value on one-minute base is calculated to smooth the variability. After that, steady state conditions of the system are ensured by applying some filtering criteria which all must be verified simultaneously; if only one of the filter fails for a certain minute, the whole data for that minute are neglected in the analysis.

The set of variables and filters adopted in the process are summarized in Table 3.

Fig. 6 shows the application of the filter applied to the solar irradiance.

\subsection{Results}

Firstly, Fig. 7 shows one typical day of experimentation, where startup/shutdown cycles of the circulating pump of the PV/T panels loop were done to evaluate the increase of performance when the

Table 3

Variable used for filtering and thresholds.

\begin{tabular}{lr}
\hline Flow Rate Condenser - Standard Deviation & $\sigma(\dot{V})<0.011 / \mathrm{min}$ \\
Flow Rate Evaporator - Standard Deviation & $\sigma(\dot{V})<0.051 / \mathrm{min}$ \\
$T_{\text {in }}, T_{\text {out }}$ - Variation between two minutes & $\Delta T<0.2^{\circ} \mathrm{C}$ \\
$T_{\text {in }}, T_{\text {out }}$ - Standard Deviation & $\sigma(T)<0.05^{\circ} \mathrm{C}$ \\
Compressor Consumption - Standard Deviation & $\sigma\left(\dot{W}_{\text {comp }}\right)<5 \mathrm{~W}$ \\
Solar Irradiance - Mean Value & $G>100 \mathrm{~W} / \mathrm{m}^{2}$ \\
Solar Irradiance - Standard Deviation & $\sigma(G)_{\%}<1 \%$
\end{tabular}

system operated in dual-source mode. The graph shows that, when the $\mathrm{PV} / \mathrm{T}$ panels are working, after a short period of stabilization of outlet temperature of the $\mathrm{PV} / \mathrm{T}$ panels, the superheated vapor temperature is higher compared to the previous working condition and also higher compared to the ambient temperature. In these conditions, the I-DSHP outperforms ASHP, confirming the potentialities of the concept.

Fig. 8 shows the comparison of the superheated vapor temperature between the HP operating in standard air-source mode and in the dualsource mode, after the filtering process. It is clearly visible that in all the experimental conditions, the innovative layout have a higher vapor temperature than a standard ASHP meaning better performance of the integrated dual-source system. The temperature increase can be as high as $3 \mathrm{~K}$, always above the ambient temperature.

Furthermore, results in terms of COP for all the filtered data as a function of the ambient temperature are presented in Fig. 9. It is possible to notice that the performance of the I-DSHP mode is lower than the standard air-source mode operating condition. This is essentially caused by the high consumption of the circulating pump, which are almost half the electrical consumption of the compressor and it is related to the non-optimal sizing of the components discussed previously.

In fact, in this experimental activity, four PV/T panels with the optimum flow rate equal to $21 / \mathrm{min}$ each were installed, but the circulating pump provided at least $6 \mathrm{l} / \mathrm{min}$. The circulating pump therefore limited the opportunity to reduce the flow rate and to optimize the COP of the system.

Finally, from the point of view of the PV/T performance, coupling $\mathrm{PV} / \mathrm{T}$ with a HP enhances both thermal and electrical efficiency, because the PV/T panels operate at a lower temperature compared to a condition where they have to produce directly the thermal demand in a residential scenario. The thermal efficiency can be as high as $30 \%$ also in very cold conditions as $0{ }^{\circ} \mathrm{C}$. In some cases, the PV/T temperature can be below the ambient one leading to very high thermal efficiencies, as measured in (Simonetti et al., 2018). At the same time, electrical efficiency increases due to the cooling effect of the solar cells, with a maximum absolute gain of $0.5 \%$ compared to a standard PV module.

\section{Numerical analysis}

\subsection{HP model}

After the experimental activity which validated the concept, an analytical model is developed to optimize the design of the system and its performance. The HP model solves heat and mass balances assuming stationary conditions, neglecting the transient effect of solar radiation variation. All the components of the HP except the innovative evaporator and $\mathrm{PV} / \mathrm{T}$ modules are considered as black-boxes, with governing equations to describe their physical behavior. For the I-DSE, a finite volume approach was used considering the 3D nature of the heat exchange in this component.

\subsubsection{Compressor}

The behavior of the compressor is described with polynomial equations to determine the refrigerant flow rate $\dot{m}_{r e f r}$ and the electrical 


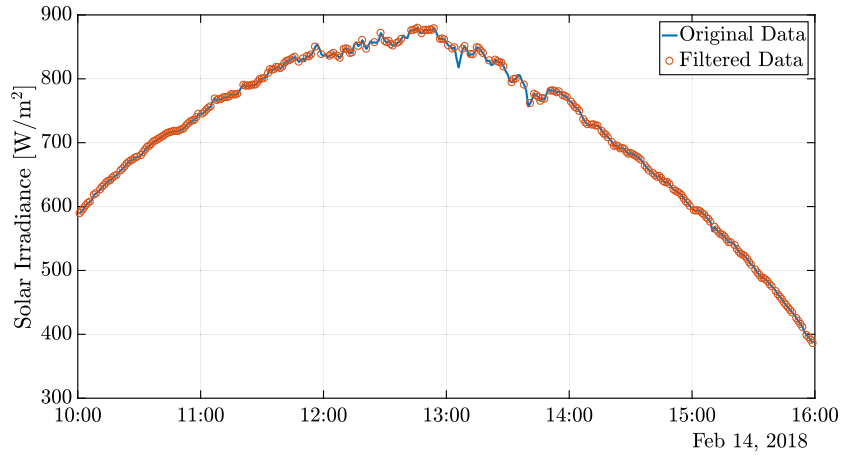

Fig. 6. Example of data filtering.

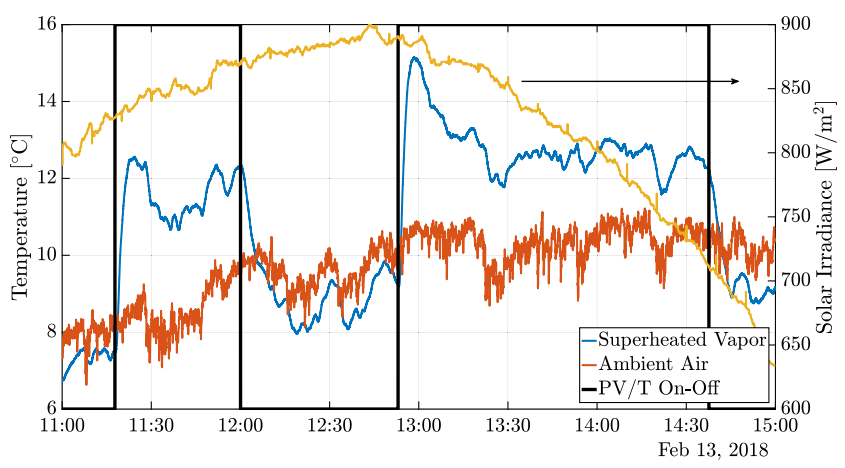

Fig. 7. Representation of the superheated vapor temperature for a representative day as a function of working conditions for I-DSHP experimental campaign. Yellow line represents the solar irradiance. (For interpretation of the references to color in this figure legend, the reader is referred to the web version of this article.)

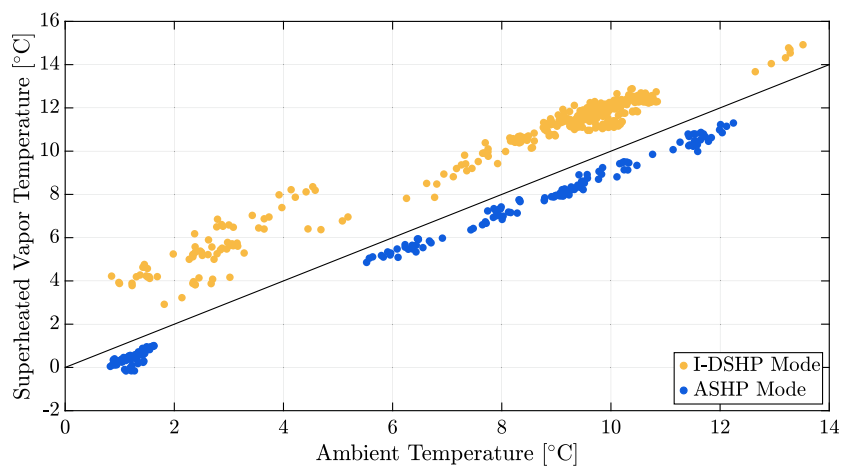

Fig. 8. Representation of the superheated vapor temperature as a function of ambient temperature for I-DSHP experimental campaign.

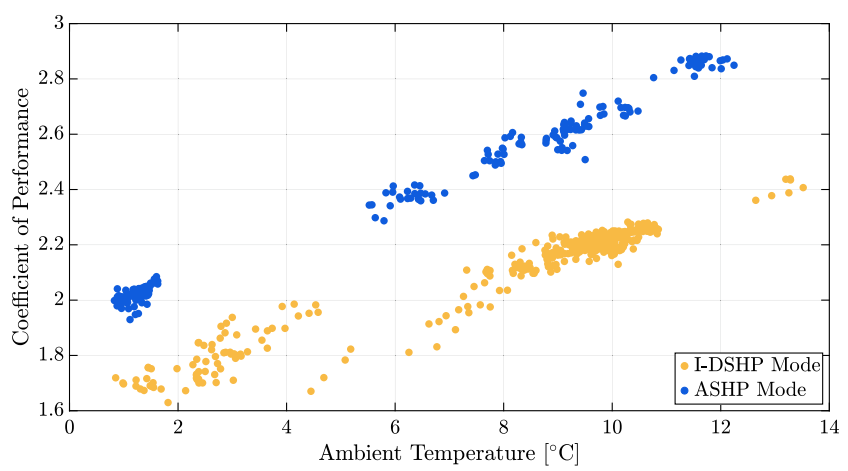

Fig. 9. Representation of the coefficient of performance as a function of ambient temperature for I-DSHP experimental campaign. power consumption $\dot{W}_{\text {comp }}$ as functions of condensing and evaporating temperatures $T_{c}$ and $T_{e}$, as shown in Eqs. 3 and 4.

$\dot{m}_{\text {refr }}=a_{0}+a_{1} T_{e}+a_{2} T_{c}+a_{3} T_{e}^{2}+a_{4} T_{e} T_{c}+a_{5} T_{c}^{2}+a_{6} T_{e}^{3}+a_{7} T_{e}^{2} T_{c}+a_{8} T_{e} T_{c}^{2}+a_{9} T_{c}^{3}$

as the following equation shows the electrical power consumption:

$\dot{W}_{\text {comp }}=b_{0}+b_{1} T_{e}+b_{2} T_{c}+b_{3} T_{e}^{2}+b_{4} T_{e} T_{c}+b_{5} T_{c}^{2}+b_{6} T_{e}^{3}+b_{7} T_{e}^{2} T_{c}+b_{8} T_{e} T_{c}^{2}+b_{9} T_{c}^{3}$

Coefficients $a_{i}$ and $b_{i}$ of the polynomial functions are evaluated by manufacturers at defined conditions and are functions of the compressor frequency, which can be varied between $50 \mathrm{~Hz}$ and $100 \mathrm{~Hz}$. The compressor used in this work (Emerson ZH06K1P-PFZ (Emerson, 2013)) is a constant speed type, but it was assumed to utilize it as a variable speed one, due to the importance to utilize this typology of machine in order to optimize the performance of the system. Using the model developed by Winandy et al. (2002), physical parameters of the original compressor were found. Then, according to Cuevas and Lebrun (2009), the functioning of the compressor was extended to different rotation frequencies. Finally, dependence of original coefficients $a_{i}$ and $b_{i}$ from the compressor frequency was obtained and corrected with the proper functions for different superheating conditions (Simonetti et al., 2017).

The enthalpy at the outlet of the compressor can be evaluated considering that $10 \%$ of the total compressor power is dissipated, as Eq. (5) shows:

$h_{2}=h_{1}+0.9 \cdot \frac{\dot{W}_{\text {comp }}}{\dot{m}_{\text {refr }}}$

\subsubsection{Condenser}

The condenser is a plate heat exchanger and is modeled by means of Eq. (6):

$\dot{Q}_{\text {condenser }}=\sum_{i=0}^{\text {zones }} U_{i} \cdot A_{i} \cdot L M T D_{i}$

The Logarithmic Mean Temperature Difference (LMTD) of each zone has to be evaluated. Thus, the condenser is divided into two parts: the de-superheating zone and the condensing zone. For the two modeled sections, thermal transmittance $U$ is calculated as shown in Eq. (7).

$U=\left(\frac{1}{h_{\text {conv }, \text { refr }}}+\frac{t_{\text {plate }}}{k_{\text {plate }}}+\frac{1}{h_{\text {conv,water }}}\right)^{-1}$

The convective heat transfer coefficient $h_{\text {conv }}$ is determined using the correlation of Kim (1999) for single-phase fluids and the modified Shah's correlation (Shah, 1979) for the two-phase refrigerant fluid.

With the aim of enhancing model accuracy, pressure drops are considered. Longo and Zilio's correlation (Longo and Zilio, 2013) is used to represent the physical behavior of the condensation, while in the desuperheating section the correlation of Martin (1996) is implemented.

\subsubsection{Expansion valve}

The working principle of the expansion valve is described by an isenthalpic transformation, where the refrigerant undergoes a pressure drop with no enthalpy variation. Eq. (8) expresses this behavior:

$h_{3}=h_{4}$

\subsubsection{Integrated dual-source evaporator}

Integrated dual-source evaporator model is based on a standard finned tube heat exchanger modeling, developed using a finite volume approach, according to (Joppolo et al., 2015). The heat exchanger is divided into small, tube-centered elemental volumes and mass, momentum and energy equations are applied to each elemental volume and solved introducing the following assumptions: 
- the heat exchanger operates in a steady-state regime;

- potential and kinetic energy are negligible;

- phase change occurs when bulk enthalpy reaches saturated enthalpy at given pressure;

- radiation heat transfer with the surrounding and axial heat conduction through tube thickness are negligible;

- joints, splits, return bends and headers are adiabatic;

- refrigerant, secondary fluid and air properties are constant at the elemental volume level;

- water condensation or frost formation are not considered;

- a constant superheating of $5 \mathrm{~K}$ is used as well as R410A as the refrigerant fluid.

The I-DSE modeled is organized in rows, where refrigerant or secondary fluid flow, and in circuits, which can have different arrangements for the two fluids. The model is written in Matlab ${ }^{\circledR}$ and it is possible to create complex circuitries to identify the optimal configuration for the innovative heat exchanger. Fig. 10 shows a generic tube elemental volume. The refrigerant mass, momentum and energy equations applied to each elemental volume are described in the following equations:

$\dot{m}_{f}(i, j, k)=\dot{m}_{f}(i, j, k+1)$

$p_{f}(i, j, k)=p_{f}(i, j, k+1)+\Delta p_{f, f r i c}(i, j, k)+\Delta p_{f, a c c}(i, j, k)$

$\dot{m}_{f}(i, j, k) \cdot h_{f}(i, j, k)=\dot{Q}(i, j, k)+\dot{m}_{f}(i, j, k+1) \cdot h_{f}(i, j, k+1)$

where $\Delta p_{f, \text { fric }}$ represents the friction term of the pressure drop, which is evaluated with the correlation of Celen et al. (2013) in a single phase flow, and with the correlation of Goto et al. (2001) for two phase flow. The acceleration term $\Delta p_{r, a c c}$ is calculated using the following equation, for two phase flow, and neglected otherwise:

$$
\begin{aligned}
\Delta p_{r, a c c}(i, j, k)= & G_{r}^{2}(i, j, k) \cdot\left\{\frac{[1-\chi(i, j, k+1)]^{2}}{[1-\xi(i, j, k+1)] \cdot \rho_{l i q}}+\frac{\chi^{2}(i, j, k+1)}{\xi(i, j, k+1) \cdot \rho_{\text {vap }}}\right. \\
& \left.-\frac{[1-\chi(i, j, k)]^{2}}{[1-\xi(i, j, k)] \cdot \rho_{\text {liq }}}-\frac{\chi^{2}(i, j, k)}{\xi(i, j, k) \cdot \rho_{\text {vap }}}\right\}
\end{aligned}
$$

where $G_{r}$ is the specific flow rate of a single channel, $\chi$ is the vapor quality in the refrigerant flow and $\xi$ is the void fraction evaluated with the homogeneous method.

For the air-side, mass and energy equations are:

$\dot{m}_{a}(i, j, k)=\dot{m}_{a}(i, j+1, k)$

$\dot{m}_{a}(i, j, k) \cdot h_{a}(i, j, k)=\dot{Q}(i, j, k)+\dot{m}_{a}(i, j+1, k) \cdot h_{a}(i, j+1, k)$

Regarding momentum equation, the influence of pressure variation on heat transfer rate can be neglected because the fluid does not change its phase. Consequently, the momentum equation is solved separately from the energy equation and the whole pressure drop at evaporator scale is calculated, using the following equation:

$p_{a, \text { in }}=p_{a, \text { out }}+\Delta p_{a, \text { fric }}$

where the friction term is calculated using the correlation proposed by Wang et al. (1997).

The model evaluates, for each finite volume, the heat exchanged using the $\in-N T U$ method:

$\dot{Q}=\epsilon \cdot M I N\left(\dot{m} \cdot c_{p}\right) \cdot\left(T_{f}-T_{a}\right)$

where $\epsilon$ is the effectiveness calculated using different formulations for single phase and two phase (ESDU, 2007). The following equations are adopted for the Number of Transfer Units (NTU) parameter:

$N T U=\frac{U A}{M I N\left(\dot{m} \cdot c_{p}\right)}$

$U A=\left(R_{f}+R_{\text {wall }}+R_{a}\right)^{-1}$
The three thermal resistances in the equations are evaluated with the following criteria:

$R_{f}$ The fluid convective heat transfer coefficient is determined using the correlation proposed by Copetti et al. (2004) for the single phase flow, and the correlation of Thome et al. (1997) for the two phase flow.

$R_{\text {wall }}$ The thermal resistance of the wall is evaluated with lumped parameter method.

$R_{a}$ The air convective heat transfer coefficient is calculated according to the Wang et al. (1997) correlation, using the fin efficiency calculated from the Schmidt formulation (Schmidt, 1949).

After the calculation of the heat transferred from the $\epsilon-N T U$ method, enthalpies of the air, refrigerant and secondary fluid can be determined from the energy balances. Then, the pressure drops are determined and used to calculate the temperatures and physical properties. An iterative method is required for the solution of this process.

The boundary conditions of the model are:

- inlet status of refrigerant and secondary fluid (mass flow rate, temperature, pressure and enthalpy);

- inlet status of the air flow (mass flow rate, temperature, pressure and humidity ratio);

- geometry of the heat exchanger.

The model finds the conditions at the outlet of the three flows and the heat transferred.

\subsection{5. $P V / T$ modules}

For $\mathrm{PV} / \mathrm{T}$ modules which are roll-bond type, with polycrystalline solar cells, both thermal and electrical modeling are needed. Thermal behavior is described by Eq. (19), which takes into account optical and thermal losses. The two coefficients $\eta_{o p t}$ and $a_{1}$ were experimentally determined at the SolarTech ${ }^{\mathrm{Lab}}$ (Gabrielli et al., 2019).

$\eta_{\text {th }}=\eta_{\text {opt }}-a_{1} \cdot \frac{\left(T_{o u t}+T_{\text {in }}\right) / 2-T_{a m b}}{G_{T}}=\frac{\dot{V} \cdot \rho \cdot c_{p} \cdot\left(T_{\text {out }}-T_{\text {in }}\right)}{G_{T} \cdot A_{\text {panel }} \cdot N_{\text {panels }}}$

The electric behavior of the PV cells is modeled using the power coefficient approach (Chow, 2010), as shown in Eq. (20).

$\eta_{e l}=\eta_{e l, R E F} \cdot\left[1-\gamma \cdot\left(T_{\text {cell }}-T_{\text {cell }, R E F}\right)\right]=\frac{\dot{W}_{\text {panels }}}{G_{T} \cdot A_{\text {panel }} \cdot N_{\text {panels }}}$

where $\eta_{\text {el,REF }}$ and $T_{\text {cell,REF }}$ are taken from the datasheet of the panel. $T_{\text {cell }}$ is determined summing up a constant value, equal to $10 \mathrm{~K}$ according to results obtained from the experimental analysis, to the mean temperature of the fluid circulating on the panel $\bar{T}_{\text {fluid }}$. Table 4 summarizes the main characteristics of the panels used.

Pressure drops of $\mathrm{PV} / \mathrm{T}$ panels are modeled using a polynomial curve extrapolated from tests done by the manufacturer, as shown in

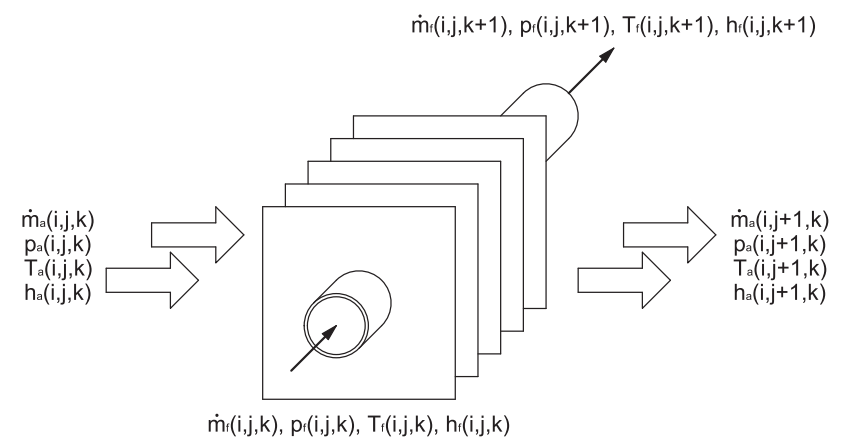

Fig. 10. Generic tube elemental volume with fluid and air parameters (Joppolo et al., 2015). 
Eq. (21).

$\Delta p_{\text {panel }}=980.9 \cdot \dot{V}^{2}+4475 \cdot \dot{V}$

where the volumetric flow rate $\dot{V}$ is expressed in $[1 / \mathrm{min}]$.

\subsubsection{Hydraulic loop}

Secondary hydraulic loop is considered in the model including a pump, whose power consumption is modeled as follow:

$\dot{W}_{\text {pump }}=\dot{V} \cdot \frac{\Delta p}{\eta_{\text {pump }}}$

Pump efficiency is assumed to be constant equal to $15 \%$, a typical value for small scale centrifugal pumps (Grundfos, 2018) and Table 5 summarizes the characteristic of the hydraulic circuit.

\subsection{Circuitry configurations}

Different configurations of the innovative heat exchanger were examined to identify the best circuitry in terms of SAHP system performance. The I-DSE used presents 36 tubes in the frontal area and two rows for the refrigerant flow, which is a standard layout of a commercial air evaporator. The tubes array is divided into four identical circuits, with nine tubes each, to reduce refrigerant-side pressure drops.

Regarding the secondary fluid rows, six layouts were studied:

Case A two rows of secondary fluid interchanged with the refrigerant rows in a counterflow configuration for both the refrigerant and the secondary fluid. This is the simplest configuration, with a first row to heat the air and a second row to introduce an extra heat in the evaporating zone;

Case B two rows before the refrigerant ones, following the air flow, in a counterflow asset. This configuration aims at uniformly increasing the air temperature in the secondary fluid rows, so to have at the inlet of the refrigerant rows a similar working conditions of a standard air evaporator with an uniform temperature, but with better performance;

Case C similar to the Case B but with a zigzag pattern of the secondary fluid. This is designed to have the temperature of the air as high as possible in the zone where the superheating of the refrigerant occurs;

Case $\mathrm{D}$ the rows disposition is like the Case $\mathbf{C}$, but with all the tubes of the secondary fluid in parallel. This adds to the benefit of the previous configuration the reduction of the pressure drops in the secondary fluid loop;

Case $\mathrm{E}$ it is the same of the Case A but with only one row for the secondary fluid before the refrigerant rows following the flowing of the air so to minimize the modifications of the heat exchanger compared to a standard air evaporator and reduce air-side pressure drops;

Case $\mathrm{F}$ equal to the Case A but with only one tube for both the circuits corresponding to 36 circuits of one tube instead of four circuits of nine tubes. This configuration emulates the perfect counterflow between refrigerant and secondary fluid, with a very low pressure drops.

All the cases described are shown in Figs. 11 and 12.

\subsection{Model recap and data}

The model of the I-DSE was embedded in a complete HP model (with compressor, condenser and expansion valve governing equations and refrigerant thermophysical properties) and coupled with a model of $\mathrm{PV} / \mathrm{T}$ panels, according to the one developed by (Simonetti et al., 2017). The system of non-linear equations was solved with the function fsolve available in the MATLAB ${ }^{\circledR}$ library. In addition to the physical model, an optimization tool was used to maximize the performance parameter COP. The optimization was done with the function fmincon varying the volumetric flow rate of the $\mathrm{PV} / \mathrm{T}$ panels and the compressor frequency inside physical constrains, which are $0.008 \overline{3} \mathrm{l} / \mathrm{s}(0.5 \mathrm{l} / \mathrm{min})$ and $0.03 \overline{3} \mathrm{l} / \mathrm{s}(2 \mathrm{l} / \mathrm{min})$ for each PV/T module and $50 \mathrm{~Hz}$ and $100 \mathrm{~Hz}$ for the compressor. Starting from a design condition, the model was used to assess the performance of all the integrated dual-source systems at different environmental conditions.

The working fluid considered was R410A and a mixture of $30 \%$ of ethylene glycol and $70 \%$ of water in volume was used as the secondary fluid to avoid freezing problems. Furthermore, the number of PV/T panels coupled with the HP was set to 12 , each with $250 \mathrm{~W}$ of power peak (SoLink, 2018) in order to obtain an overall power peak of $3 \mathrm{~kW}$ that is a standard configuration in a Italian residential context.

The HP obtained has a nominal heating capacity equal to $8.5 \mathrm{~kW}$ and a COP equal to 3.2 and Table 6 resumes the temperature used in the design process, where SC and PR stand for secondary fluid loop and primary fluid loop respectively.

\subsection{Results}

The performance of each of the six configurations previously described is evaluated varying the solar irradiance and the ambient temperature, from $0 \mathrm{~W} / \mathrm{m}^{2}$ to $1000 \mathrm{~W} / \mathrm{m}^{2}$ and from $-15^{\circ} \mathrm{C}$ to $20^{\circ} \mathrm{C}$ respectively, with fixed conditions for the condenser water flow which coincides to the design. The comparison is performed using the COP and $\mathrm{COP}^{*}$ as key performance indicators, according to the Eqs. (1) and (2).

Firstly, results in terms of COP as function of the ambient temperature and solar irradiance for the reference configuration (case A) are showed in Fig. 13. The COP increases with ambient temperature and solar irradiance as expected, reaching very high values. At high ambient temperature, COP isolines become closer and straighter.

The former trend is connected to the double positive effect caused by increasing the ambient temperature: the higher the ambient temperature, the higher the heat produced by $\mathrm{PV} / \mathrm{T}$ panels as consequence of the lower thermal losses and the higher the capability of the air to exchange heat with the secondary and the refrigerant fluids. These two phenomena combined together cause the greatest increase of the COP. The straighter trend of the isolines is related to the sizing of the I-DSE: at low temperature the heat exchanger is oversized and all the heat coming from the solar field is transferred to the refrigerant fluid; vice versa at high ambient temperature the evaporator is undersized and the performance increase is more limited and more linearly proportional to the increase of solar irradiance. The performance maps discussed so far where determined optimizing the compressor frequency and the secondary fluid flow rate so to maximize the COP.

An analysis of the optimization results shows that the compressor frequency and the secondary fluid flow rate are always at their lowest possible value. For the first parameter, it is already known in literature that the HP has higher COP with a lower rotation frequency of the compressor, because the power consumption decreases more quickly than the reduction of the useful heat produced (Molinaroli et al., 2019). Regarding the second parameter, there is no convenience to increase the flow rate of the secondary fluid: the additional heat introduced in the cycle due to a higher heat transfer coefficient and lower average temperature does not balance the additional consumption of the circulating pump, which grows quadratically (Simonetti, 2019).

Fig. 14 on the left shows the results in terms of the COP*.

Table 4

Characteristic of PV/T panels.

\begin{tabular}{ccccccc}
\hline $\mathrm{A}_{\text {panel }}$ & $\eta_{\text {opt }}$ & $\mathrm{a}_{1}$ & $\eta_{\text {el,REF }}$ & $\dot{W}_{R E F}$ & $\gamma$ & $\mathrm{T}_{\text {cell, REF }}$ \\
\hline $1.63 \mathrm{~m}^{2}$ & 0.528 & $13.658 \mathrm{~W} / \mathrm{m}^{2} \mathrm{~K}$ & 0.153 & $250 \mathrm{~W}$ & $0.42 \% / \mathrm{K}$ & $56{ }^{\circ} \mathrm{C}$ \\
\hline
\end{tabular}


Table 5

Characteristic of secondary hydraulic circuit

\begin{tabular}{ccc}
\hline Tubes Length & Losses & Volumetric Ethylene Glycol Fraction $\left(\mathrm{X}_{S C}\right)$ \\
\hline $7 \mathrm{~m}$ & $9(\mathrm{~Pa} / \mathrm{m}) \cdot(\mathrm{l} / \mathrm{min})$ & 0.3 \\
\hline
\end{tabular}

Considering the electricity produced by $\mathrm{PV} / \mathrm{T}$ panels, the overall consumption is remarkable reduced and consequently the $\mathrm{COP}^{*}$ reaches very high values. The influence of the ambient temperature variation on this parameter is reduced compared with the impact of the solar irradiance, due to the dominant effect of the increased electrical production compared to an increased thermodynamic performance related to a higher evaporation temperature. This trend stops when the denominator of Eq. (2) becomes very small: in this condition, a little variation of the HP performance linked to a variation of ambient temperature significantly affects the COP*. Obviously, with no solar irradiance, the values of $\mathrm{COP}^{*}$ and COP coincide. Finally, the red zone in the top part of the contour plot represents the conditions where $\mathrm{COP}^{*}$ becomes negative: the electricity produced by $\mathrm{PV} / \mathrm{T}$ modules is higher than the system consumptions, achieving the self-consumption condition and also a positive net electrical power production, useful to supply the others load presents in a residential application.

On the right side of Fig. 14, the fraction of the heat produced by PV/ $\mathrm{T}$ panels compared to the one entered and used in the HP cycle is presented. A ratio equal to 1 corresponds to the ideal condition where the heat exchanged in the integrated dual-source evaporator comes from the solar field and the outlet air temperature coincides with the inlet one. With decreasing ambient temperature, this phenomenon occurs at lower solar irradiance, due to the fact that the evaporation load reduces more rapidly than the heat produced by $\mathrm{PV} / \mathrm{T}$ panels. In addition, it is possible to observe that also with solar radiation low as $200 \mathrm{~W} / \mathrm{m}^{2}$, the heat provided by the Sun is around $25 \%$, which is an appreciable value. A more complex optimization of the heat exchanger could consider to oversize the component (so to introduce more solar energy at low irradiance conditions) or to analyze the variation of the rotational speed of the fan (kept constant in this work).

The graph on the left in Fig. 15 presents the COP as a function of the ambient temperature and solar irradiance for the I-DSE together with the case of a standard ASHP (dashed line), obtained using the original version of the evaporator structure with only two rows of refrigerant. As stated, the formation of brine was not considered in this work. In all the simulated conditions with a solar irradiance above zero, the innovative system has a higher COP confirming the potentialities of the idea. During the night, performance is roughly the same for the two systems, while in the dual-source system the circulating pump is switched on. This means that the extra consumption of this component is balanced by the extra heat introduced in the HP cycle, reaching the same COP in both configurations. Moreover, a simulation with no flow rate in the $\mathrm{PV} / \mathrm{T}$ loop was done, outlining that the I-DSHP in air asset has the same performance of a standard ASHP, with a maximum relative difference of $0.35 \%$, confirming that the introduction of other rows doesn't significantly reduce the evaporator performance.

The graph on the right in Fig. 15 explains the relative performance increase in percentage with compared to the condition without solar irradiance, witch corresponds to the air-source asset. Results show that an improvement above $10 \%$ is achievable, with a higher effect at low ambient temperature, related to the oversizing of the evaporator in these conditions.

One of the objectives of this work is to find the optimal circuitry configuration for an integrated dual-source evaporator. The comparison between the six cases, see Section 4.2, is carried out in terms of COP. Considering the number of cases and the necessity to analyze all the environmental conditions, a map with the best configuration for each combination of ambient temperature and solar irradiance is created and is reported in Fig. 16. With this procedure, it is possible to identify the operating range where a circuitry is more performing compared to the others.

In the graph on the left, it can be noted that case A has a large zone where outperforms the other configurations. In the same graph, a contour plot was added to visualize how much the other cases outperforms case A in relative percentage terms. The difference is very limited reaching a maximum of $2 \%$ for case $\mathrm{C}$, which shows the highest differences. The circuitry of this case is designed to maximize the temperature of the air in the superheating zone of the evaporator, and this is more relevant under low solar irradiance and in cold sunny day condition. Cases B, D and E have higher performance in the corners of the graph, but as mentioned before the relative advantage is very limited. Furthermore, the case $\mathrm{F}$ is not present in the graph, meaning that this circuitry has no benefits in the considered application due to the low mass flow rate of the refrigerant in the tubes.

Finally, the graph on the right of the Fig. 16 shows the same comparison previously described in terms of the electrical power produced by the solar field. The contour plot describes the difference between the production of other cases and case $\mathrm{A}$, divided by the reference power at Standard Test Conditions (STC). It is possible to see that case A has the larger area and only cases B and D reach higher values, with a maximum of gain of $1 \%$.

Both COP and electric results support the adoption of case A as the optimal design for the selected HP design.

\section{Conclusions}

This work analyzed the performance of an Indirect Solar-Assisted
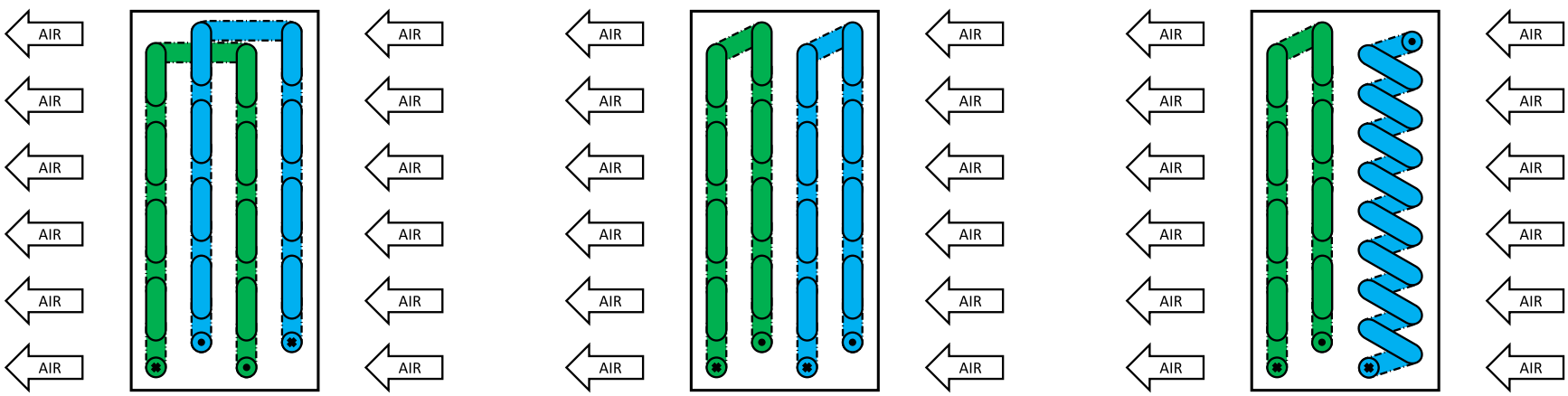

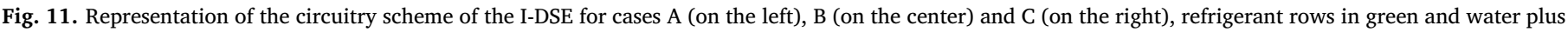
glycol mixture rows in blue. (For interpretation of the references to color in this figure legend, the reader is referred to the web version of this article.) 

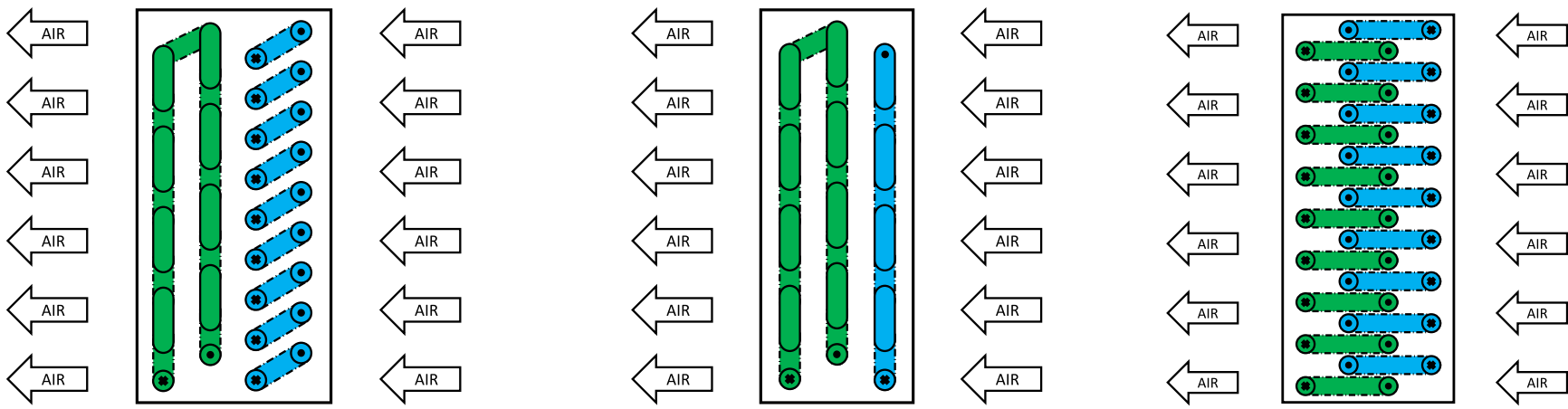

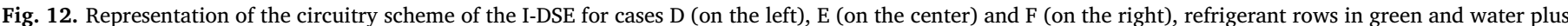
glycol mixture rows in blue. (For interpretation of the references to color in this figure legend, the reader is referred to the web version of this article.)

Table 6

Temperatures at the design condition.

\begin{tabular}{cccccccc}
\hline $\mathrm{T}_{e}$ & $\Delta \mathrm{T}_{\text {sh }}$ & $\mathrm{T}_{S C, \text { in }}$ & $\mathrm{T}_{S C, \text { out }}$ & $\mathrm{T}_{c}$ & $\Delta \mathrm{T}_{\text {sub }}$ & $\mathrm{T}_{P R, \text { in }}$ & $\mathrm{T}_{P R, \text { out }}$ \\
\hline $2{ }^{\circ} \mathrm{C}$ & $5 \mathrm{~K}$ & $10{ }^{\circ} \mathrm{C}$ & $7{ }^{\circ} \mathrm{C}$ & $50{ }^{\circ} \mathrm{C}$ & $0 \mathrm{~K}$ & $40{ }^{\circ} \mathrm{C}$ & $45^{\circ} \mathrm{C}$
\end{tabular}

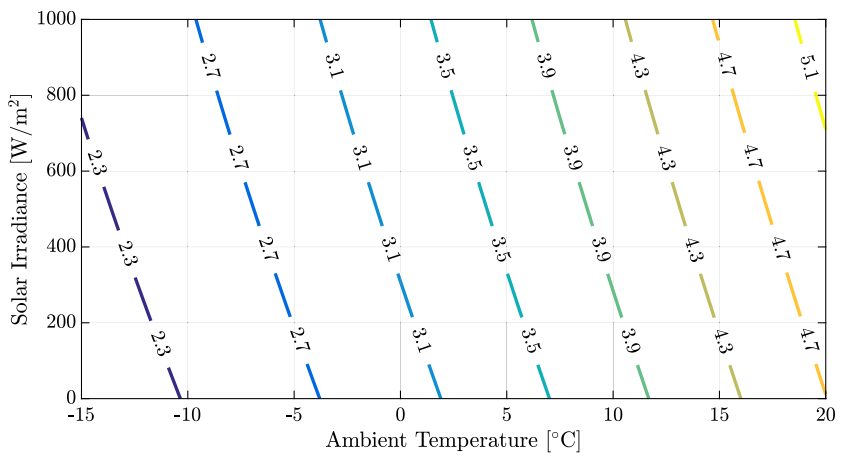

Fig. 13. Lines represents the COP as a function of ambient temperature and solar irradiance for the configuration A of I-DSE.

Heat Pump (I-SAHP) with an Integrated Dual-Source Evaporator (IDSE). An experimental campaign was conducted in an outdoor laboratory with a prototype Heat Pump (HP) and a commercial version of a I-DSE, to confirm the feasibility of the system and the concept potentialities. Then, a model was developed in Matlab ${ }^{\circledR}$ to identify the optimal configuration between six different circuitries proposed.

Regarding the experimental analysis, the superheated vapor temperature in the proposed configuration presents higher values, with a maximum increment of $3 \mathrm{~K}$, and in every condition higher than the ambient temperature, in a range between $0{ }^{\circ} \mathrm{C}$ and $14^{\circ} \mathrm{C}$. In addition, also the performance of Photovoltaic/Thermal (PV/T) panels were analyzed, showing that the thermal efficiency presents values higher than $30 \%$ at low ambient temperature, and the electrical efficiency is always higher that the one of a standard Photovoltaic (PV) panel when the solar field is working. These results confirmed the interest in the proposed innovative layout.

Then, a numerical model was developed to identify the optimal design of the integrated evaporator considering the overall HP system. After the sizing of all the components, numerical results have shown that the Coefficient Of Performance (COP) of the entire system is high, as high as 5, with a trend that follows the variation of ambient temperature and solar irradiance. Considering also the electrical production of the $\mathrm{PV} / \mathrm{T}$ panels using the modified COP parameter, the performance of the system considerably increases with the solar irradiance, reaching negative values of $\mathrm{COP}^{*}$ and a self-consumption condition around $800 \mathrm{~W} / \mathrm{m}^{2}$. The work also underlined that the heat introduced in the HP cycle from the solar fields is high, with a percentage of $25 \%$ referred to the heat exchanged by the refrigerant fluid with a solar irradiance of $200 \mathrm{~W} / \mathrm{m}^{2}$.

A comparison with a standard Air-Source Heat Pump (ASHP) was done, and the results showed that in all conditions the system proposed has higher COP, with a relative improvement of $14 \%$ maximum, corresponding to an absolute increase of 0.4 , and roughly the same performance with no solar radiation, confirming the interest in this technology. Lastly, the comparison of the six circuitries illustrated that case A has higher performance in the majority of the ambient conditions analyzed in terms of COP and electrical production, and negligible differences with other cases in the unfavorable environmental conditions.

Future works shall consider more complex sizing of the I-DSE in order to maximize the benefits of the innovative component and a techno-economic evaluation of the concept in a yearly based analysis.
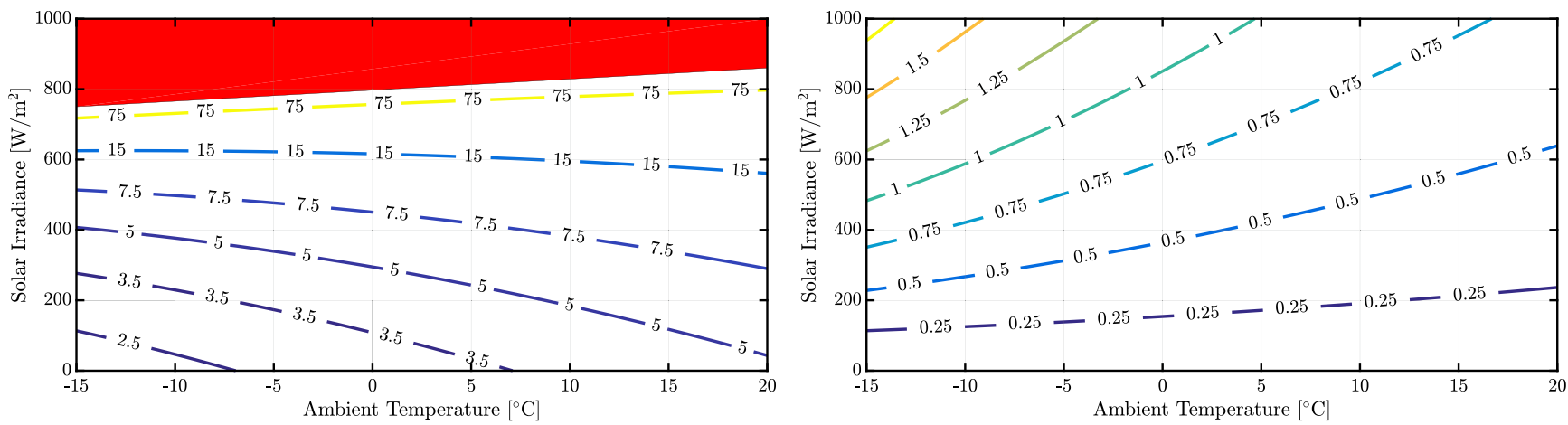

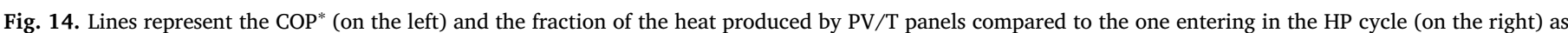

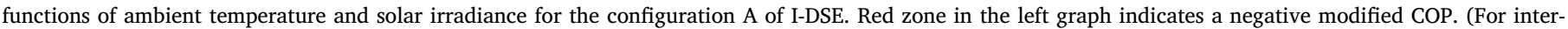
pretation of the references to color in this figure legend, the reader is referred to the web version of this article.) 

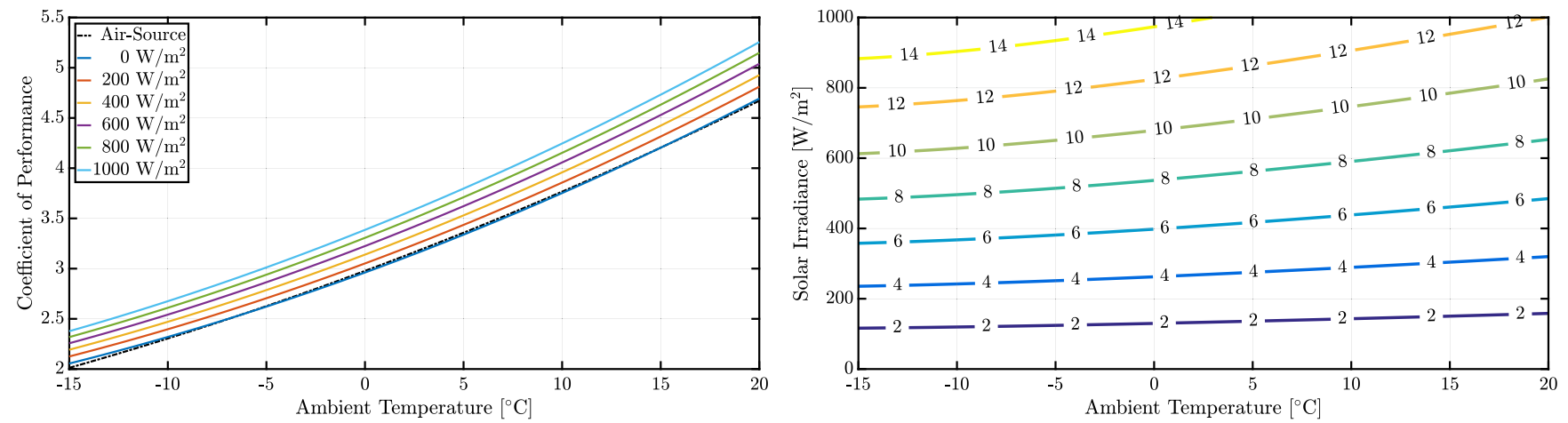

Fig. 15. Representation of COP for the I-DSHP (solid lines) and for a standard ASHP (dashed line) (left) and of COP relative improvement in percentage with the innovative HP (right) as functions of ambient temperature and solar irradiance.
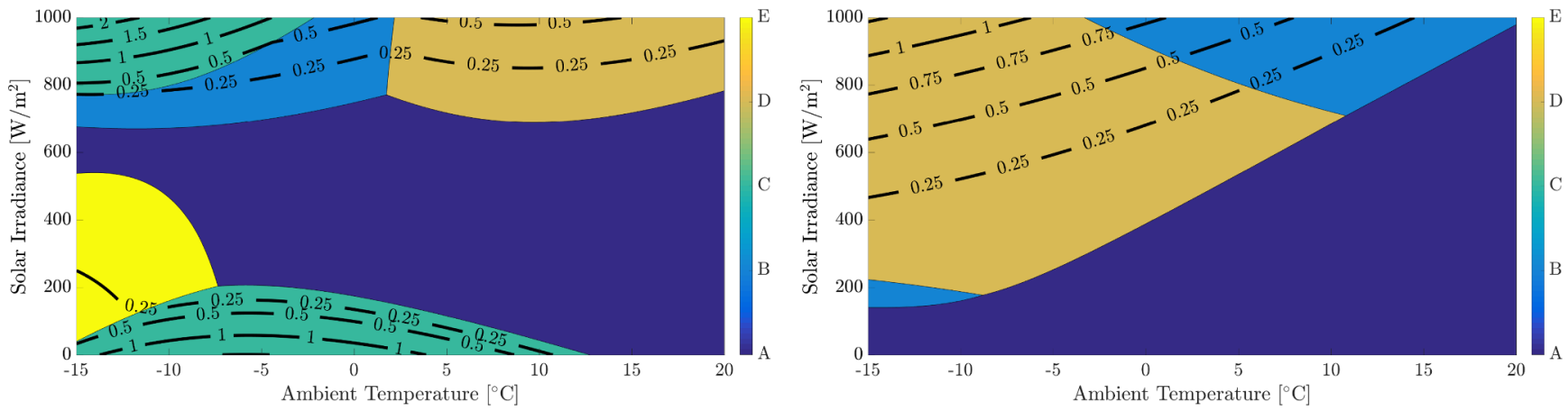

Fig. 16. Representation of the best configuration in terms of COP (left) and of electrical power production (right) for the 6 cases analyzed as functions of ambient temperature and solar irradiance. Isolines represent the percentage relative difference (in positive) compared to case A.

\section{Declaration of Competing Interest}

The authors declare that they have no known competing financial interests or personal relationships that could have appeared to influence the work reported in this paper.

\section{References}

Besagni, G., Croci, L., Nesa, R., Molinaroli, L., 2019. Field study of a novel solar-assisted dual-source multifunctional heat pump. Renew. Energy 132, 1185-1215. https:// www.sciencedirect.com/science/article/pii/S0960148118310267.

Bombarda, P., Di Marcoberardino, G., Lucchini, A., Leva, S., Manzolini, G., Molinaroli, L., Pedranzini, F., Simonetti, R., 2016. Thermal and electric performances of roll-bond flat plate applied to conventional PV modules for heat recovery. Appl. Therm. Eng. 105, 304-313. http://www.sciencedirect.com/science/article/pii/ S1359431116308511

Buker, M.S.S., Riffat, S.B., 2016. Solar assisted heat pump systems for low temperature water heating applications: a systematic review. Renew. Sustain. Energy Rev. 55, 399-413. https://www.sciencedirect.com/science/article/pii/ S1364032115012368.

Cai, J., Ji, J., Wang, Y., Zhou, F., Yu, B., 2017. A novel PV/T-air dual source heat pump water heater system: dynamic simulation and performance characterization. Energy Convers. Manage. 148, 635-645. https://www.sciencedirect.com/science/article/ $\mathrm{pii} / \mathrm{S} 0196890417305770$

Calise, F., Dentice d'Accadia, M., Figaj, R.D., Vanoli, L., 2016. A novel solar-assisted heat pump driven by photovoltaic/thermal collectors: dynamic simulation and thermoeconomic optimization. Energy 95, 346-366. https://www.sciencedirect.com/ science/article/pii/S0360544215016345?via\%3Dihub .

Carel, 2018. Electronic expansion valves - ExV. datasheet. https://www.carel.com/ documents/10191/549934/Electronic + expansion + valves + - + ExV.pdf/ddf97b5b68f6-415f-8922-c8b678690c62.

Celen, A., Dalkilic, A.S., Wongwises, S., 2013. Experimental analysis of the single phase pressure drop characteristics of smooth and microfin tubes. Int. Commun. Heat Mass Transf. 46, 58-66. https://www.sciencedirect.com/science/article/pii/ S0735193313001061.

Chow, T.T., 2010. A review on photovoltaic/thermal hybrid solar technology. Appl. Energy 87 (2), 365-379. https://www.sciencedirect.com/science/article/pii/ S0306261909002761.

Copetti, J.B., Macagnan, M.H., De Souza, D., De Césaro Oliveski, R., 2004. Experiments with micro-fin tube in single phase. Int. J. Refrig. 27 (8), 876-883. https://www. sciencedirect.com/science/article/pii/S014070070400074X
Croci, L., Molinaroli, L., Quaglia, P., 2017. Dual Source Solar Assisted Heat Pump Model Development, Validation and Comparison to Conventional Systems. In: Energy Procedia, vol. 140. Elsevier, pp. 408-422. https://www.sciencedirect.com/science/ article/pii/S1876610217355649.

Cuevas, C., Lebrun, J., 2009. Testing and modelling of a variable speed scroll compressor. Appl. Therm. Eng. 29 (2-3), 469-478. https://www.sciencedirect.com/science/ article/pii/S1359431108001397.

Emerson, 2013. Copeland Scroll ZH*K1P Compressors. datasheet. URL https://climate. emerson.com/en-gb/shop/1/copeland-copeland-scroll-zhk1p-compressors-en$\mathrm{gb}$ ?fetchFacets = true\# facet:\&facetLimit:\&productBeginIndex:0\&orderBy:\& pageView:\&minPrice:\&maxPrice:\&pageSize:\&.

ESDU, 2007. Graphical and analytical data. In: Design and Performance Evaluation of Heat Exchangers: The Effectiveness - NTU Method, p. 269 (Chapter 3). https://www esdu.com/cgi-bin/ps.pl?sess $=$ unlicensed_1190522102521qqb\&t $=$ doc\&p $=$ esdu_ 98005d.

Gabrielli, P., Gazzani, M., Novati, N., Sutter, L., Simonetti, R., Molinaroli, L., Manzolini, G., Mazzotti, M., 2019. Combined water desalination and electricity generation through a humidification-dehumidification process integrated with photovoltaicthermal modules: design, performance analysis and techno-economic assessment. Energy Convers. Manage. X 1 (100004), 18. https://www.sciencedirect.com/science/ article/pii/S2590174519300029 .

Goto, M., Inoue, N., Ishiwatari, N., 2001. Condensation and evaporation heat transfer of R410A inside internally grooved horizontal tubes. Int. J. Refrig. 24 (7), 628-638. https://www.sciencedirect.com/science/article/pii/S0140700700000876 .

Grundfos, 2018. UPS Circulator Pumps. datasheet. https://product-selection.grundfos. $\mathrm{com} /$ product-detail.product-detail.html custid $=$ GMA\&lang $=$ ITA\& productnumber $=95906429 \&$ qcid $=544312984$.

Honda, 2018. Brazed Plates Heat Exchangers. datasheet. https://www.onda-it.com/ media/1123/d-1/t-file/BPHE-EUROPA-09 2018.pdf.

IEA, 2011. Energy-efficient Buildings: Heating and Cooling Equipment. Tech. rep. https:// webstore.iea.org/technology-roadmap-energy-efficient-buildings-heating-andcooling-equipment.

IEA, 2018a. Renewables. Tech. rep. https://webstore.iea.org/renewables-information2018.

IEA, 2018b. World Energy Statistics. Tech. rep. https://webstore.iea.org/world-energy statistics-2018.

Joppolo, C.M., Molinaroli, L., Pasini, A., 2015. Numerical analysis of the influence of circuit arrangement on a fin-and-tube condenser performance. Case Stud. Therm. Eng. 6, 136-146. https://www.sciencedirect.com/science/article/pii/ S2214157X15300083.

Kim, Y., 1999. An experimental study on evaporation heat transfer characteristics and pressure drop in plate heat exchanger (Master thesis). Yonsei University.

Lazzarin, R.M., 2012. Dual source heat pump systems: operation and performance. Energy 
Build. 52, 77-85. https://www.sciencedirect.com/science/article/pii/ S0378778812002812.

Li, H., Sun, L., Zhang, Y., 2014. Performance investigation of a combined solar thermal heat pump heating system. Appl. Therm. Eng. 71 (1), 460-468. https://www. sciencedirect.com/science/article/pii/S1359431114005602?via\%3Dihub .

Liu, H., Jiang, Y., Yao, Y., 2014. The field test and optimization of a solar assisted heat pump system for space heating in extremely cold area. Sustain. Cities Soc. 13, 97-104. https://www.sciencedirect.com/science/article/pii/S2210670714000493 .

Long, J., Zhang, R., Lu, J., Xu, F., 2019. Heat transfer performance of an integrated solarair source heat pump evaporator. Energy Convers. Manage. 184 (2018), 626-635.

Longo, G.A., Zilio, C., 2013. Condensation of the low GWP refrigerant HFC1234yf inside a brazed plate heat exchanger. Int. J. Refrig. 36 (2), 612-621. https://www. sciencedirect.com/science/article/pii/S0140700713000145 .

LuVe, 2018. Industrial Unit Coolers For Cold Rooms. datasheet. https://manuals.luve.it/ Manuals/UNITCOOLERS/CHS_LHS/files/assets/common/downloads/Assembly_ Instr CHS LHS.pdf.

Martin, H., 1996. A theoretical approach to predict the performance of chevron-type plate heat exchangers. Chem. Eng. Process. 35 (4), 301-310. https://www.sciencedirect. com/science/article/pii/025527019504129X .

MasterFlux, 2017. Brushless DC Variable Speed Compressor. datasheet. https://www. masterflux.com/userimages/SIERRA02-0434Y3_Data_Sheet.pdf.

Molinaroli, L., Lucchini, A., Pietro Maria Colombo, L., 2019. Design and commissioning of an experimental facility for performance evaluation of pure and mixed refrigerants. J. Phys: Conf. Ser. 1224 (1), 012021. https://iopscience.iop.org/article/10.1088/17426596/1224/1/012021.

Nuntaphan, A., Chansena, C., Kiatsiriroat, T., 2009. Performance analysis of solar water heater combined with heat pump using refrigerant mixture. Appl. Energy 86 (5), 748-756. https://www.sciencedirect.com/science/article/pii/ S0306261908001396.

Qu, M., Chen, J., Nie, L., Li, F., Yu, Q., Wang, T., 2016. Experimental study on the operating characteristics of a novel photovoltaic/thermal integrated dual-source heat pump water heating system. Appl. Therm. Eng. 94, 819-826. https://doi.org/10. 1016/j.applthermaleng.2015.10.126.

REN21, 2018. Renewables Global Status Report. Tech. rep. http://www.ren21.net/gsr_ 2018_full_report_en.

Schmidt, T., 1949. Heat transfer calculation for extended surfaces. Refrig. Eng. 57,
$351-357$.

Shah, M.M., 1979. A general correlation for heat transfer during film condensation inside pipes. Int. J. Heat Mass Transf. 22 (4), 547-556. https://www.sciencedirect.com/ science/article/pii/0017931079900589

Shi, G.H., Aye, L., Li, D., Du, X.J., 2019. Recent advances in direct expansion solar assisted heat pump systems: A review. Renew. Sustain. Energy Rev. 109, 349-366. https:// www.sciencedirect.com/science/article/pii/S1364032119302564.

Simonetti, R., 2019. Experimental and analytical study of solar-assisted heat pump (Ph.d. thesis). Politecnico di Milano.

Simonetti, R., Manzolini, G., Molinaroli, L., 2017. Modeling of solar assisted heat pumps combined with photovoltaic thermal modules. In: Proceedings of SWC2017/ SHC2017. International Solar Energy Society, Freiburg, Germany, pp. 1-12. http:// proceedings.ises.org/citation?doi $=$ swc.2017.33.08

Simonetti, R., Molinaroli, L., Manzolini, G., 2018. Experimental performance evaluation of PV/T panels at negative reduced temperatures. In: Proceedings of EuroSun 2018. International Solar Energy Society, Freiburg, Germany, pp. 1-10. URL http:// proceedings.ises.org/citation?doi = eurosun2018.02.23.

SoLink, 2018. PV/T SoLink. datasheet. URL https://www.solink.it/download/209/.

Thome, J.R., Favrat, D., Kattan, N., 1997. Evaporation in microfin tubes: a generalized prediction model. In: Proceedings of Convective Flow and Pool Boiling Conference II. Irsee, pp. 4.

Wang, C.C., Fu, W.L., Chang, C.T., 1997. Heat transfer and friction characteristics of typical wavy fin-and-tube heat exchangers. Exp. Thermal Fluid Sci. 14 (2), 174-186. https://www.sciencedirect.com/science/article/pii/S0894177796000568 .

Wang, G., Quan, Z., Zhao, Y., Sun, C., Deng, Y., Tong, J., 2015. Experimental study on a novel PV/T air dual-heat-source composite heat pump hot water system. Energy Build. 108, 175-184. https://www.sciencedirect.com/science/article/pii/ S0378778815302012.

Winandy, E., Saavedra, O.C.S., Lebrun, J., 2002. Experimental analysis and simplified modelling of a hermetic scroll refrigeration compressor. Appl. Therm. Eng. 22 (2), 107-120. https://www.sciencedirect.com/science/article/pii/ S1359431101000837.

Xu, J., Zhao, Y., Quan, Z., Wang, G., Wang, J., 2018. Air-water dual-source heat pump system with new composite evaporator. Appl. Therm. Eng. 141, 483-493. https:// www.sciencedirect.com/science/article/pii/S1359431117341856. 